\title{
A 10-Year Longitudinal Observational Study Of Cataplexy In A Cohort Of Narcolepsy Type I Patients
}

This article was published in the following Dove Press journal: Nature and Science of Sleep

\author{
Aljohara S Almeneessier $\mathbb{D}^{1,2}$ \\ Nouf S Alballa (iD) \\ Budoor H Alsalman' \\ Salih Aleissi' \\ Awad H Olaish (D) \\ Ahmed S BaHammam (1D) \\ 'Department of Medicine, College of \\ Medicine, the University Sleep Disorders \\ Center, Riyadh, Saudi Arabia; ${ }^{2}$ Family and \\ Community Medicine Department, \\ College of Medicine, King Saud \\ University, Riyadh, Saudi Arabia
}

Purpose: Narcolepsy type 1 (NT1) is thought to have a chronic persistent course. This study aimed to assess the natural course of cataplexy in patients with NT1 at 2, 6, and 10 years after stabilizing symptoms. Other secondary objectives included assessing sleep quality, body mass index (BMI), and comorbidities at recruitment and 10 years later.

Patients and methods: Cataplexy symptoms, the Epworth sleepiness scale (ESS), sleep quality (assessed using the Pittsburgh sleep quality index [PSQI]), BMI, and comorbid conditions were prospectively monitored in 38 patients with NT1. The study sample comprised 38 patients with narcolepsy (males $=27$ ). The mean ages at disease onset and recruitment were $17.7 \pm 5.6$ years and $24.3 \pm 8.6$ years, respectively.

Results: In $42 \%$ of the cohort, the anti-cataplectic medications were stopped at the end of the study without disturbing symptoms of cataplexy. Additionally, there was an apparent significant reduction in the frequency of cataplexy over time. The mean ESS score decreased by more than 4 points from $19.4 \pm 2.9$ to $15 \pm 4.3(\mathrm{p}<0.001)$ while on the same pharmacotherapy. The number of patients with a PSQI score of $<5$ (indicating good sleep quality) increased from $6(15.8 \%)$ to $15(39.5 \%)(\mathrm{p}=0.004)$. The BMI increased from $30 \pm 5.1$ to 33.3 $\pm 6 \mathrm{~kg} / \mathrm{m}^{2}$ ( $\left.\mathrm{p}=0.001\right)$. No changes were documented in comorbidities.

Conclusion: The findings suggest that the course of NT1 is not stable. Over a 10-year period, cataplexy symptoms improved or disappeared in a large proportion of patients, and there was an improvement in daytime sleepiness and nighttime sleep quality. More prospective studies that repeatedly monitor CSF-HCRT are needed to confirm the current findings. Keywords: body mass index, sleep quality, daytime sleepiness, Pittsburgh Sleep Quality Index

\section{Introduction}

Narcolepsy is a chronic neurological disorder affecting sleep/wakefulness regulation and causing irresistible attacks of sleep and manifestations of various rapid eye movement (REM) sleep abnormalities, including cataplexy, sleep paralysis, and hypnagogic hallucinations. ${ }^{1}$ Additionally, disturbed, fragmented nighttime sleep is one of the prominent features of narcolepsy. Usually, narcolepsy manifestations appear in the second decade of life; however, it may present during childhood. ${ }^{1,2}$ Narcolepsy is categorized into two types, narcolepsy type 1 (NT1) (with cataplexy) and narcolepsy type 2 (NT2) (without cataplexy). Globally, narcolepsy affects approximately $0.02 \%$ of adults, with great variations in prevalence, attributed to differences in the genetic background. ${ }^{3}$
Correspondence: Ahmed S BaHammam; Aljohara S Almeneessier

Sleep Disorders Center, College of Medicine, King Saud University, Box 225503, Riyadh I 1324, Saudi Arabia Tel +966-I I-467-9495

Fax +966-II-467-9179

Email ashammam2@gmail.com; aljoharas@yahoo.com 
In general, it is believed that narcolepsy with cataplexy has a stable non-remitting course. ${ }^{4}$ It is thought that daytime sleepiness and cataplexy are persistent for a lifetime in patients with NT1 as this type of narcolepsy is associated with the acute loss of $>90 \%$ of hypocretin (HCRT)-producing neurons in the hypothalamus, causing irreversible HCRT deficiency. ${ }^{4}$ The time-course of narcolepsy symptoms has not been thoroughly investigated as longitudinal studies that assessed the time-course of narcolepsy symptoms are scarce, and some of them were retrospective. ${ }^{2,5-7}$

In a recent prospective study of children with NT1, Pizza et al demonstrated that narcolepsy in this age group was characterized by an abrupt increase of sleep duration, generalized hypotonia, and motor overactivity; however, over time, cataplexy manifestations evolved into the classical cataplexy presentation (ie, brief muscle weakness episodes triggered by emotions). ${ }^{2}$ Moreover, sleep duration across the day decreased and returned to more ageappropriate levels. ${ }^{2}$ This suggests that NT1 may not have a stable course. Additionally, multiple sleep latency test (MSLT) measures have been shown to vary greatly across age. ${ }^{5,8}$ Conflicting data have been reported regarding the relationship between age and narcolepsy symptoms. While Nevsimalova et al reported that the course and severity of narcolepsy were not related to the age of disease onset, ${ }^{6}$ Furuta et al demonstrated that cataplexy severity decreased significantly in the aged group. ${ }^{9}$

Three studies have evaluated the longitudinal evolution of narcolepsy symptoms; however, they were limited by the retrospective nature of the research. ${ }^{10-12}$ While some reported no changes in daytime sleepiness, ${ }^{10,11}$ Büchele et al reported that sleepiness is not always stable, with reported spontaneous deterioration or improvement in $27 \% .^{12}$ To the best of our knowledge, no study has specifically and prospectively addressed the course of cataplexy over time.

The primary objective of this study was to investigate the natural course of cataplexy in patients with NT1 at 2, 6 , and 10 years after symptoms become stable. Other secondary objectives included reporting data on sleep quality, body mass index (BMI), and comorbidities in patients with NT1 at recruitment and 10 years later.

\section{Materials And Methods}

\section{Study Subjects}

We prospectively monitored cataplexy symptoms during the follow up visits by applying the Third Edition of the
International Classification of Sleep Disorders (ICSD-3) definition (ICSD-2 before 2014) of cataplexy, ${ }^{13,14}$ daytime sleepiness using the Epworth sleepiness scale (ESS), sleep quality (assessed using the Pittsburgh sleep quality index [PSQI]), BMI, and comorbid conditions in patients with NT1 ( $\geq 14$ years) who visited the University Sleep Disorders Center, King Saud University and have stable controlled symptoms with treatment for at least 6 months. Recruitment occurred between 2005 and 2008, and the patients were followed up for 10 years.

Inclusion criteria comprised a definite diagnosis of NT1 according to the ICSD-3criteria (American Academy of Sleep Medicine 2014) and stable symptoms with treatment for at least 6 months. ${ }^{14}$ Figure 1 demonstrates a flow chart of the study protocol and included and excluded patients. In brief, initially, 49 patients were recruited, two patients were excluded because of lack of written informed consent, one patient died, five patients were excluded due to loss of follow-up, and three were

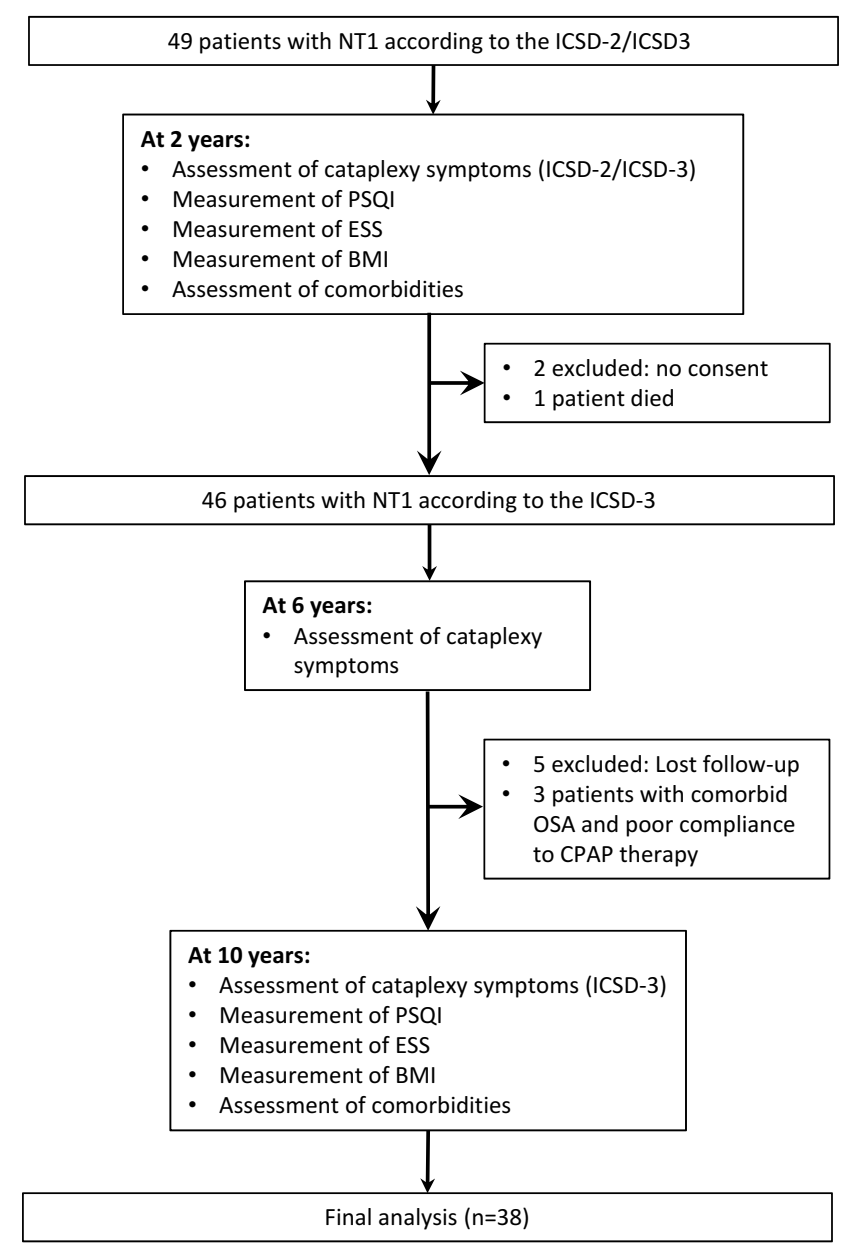

Figure I Flow chart of the study protocol and study patients. 
excluded because they had comorbid obstructive sleep apnea and were not adherent to positive airway pressure therapy. Eventually, 38 patients were included in the final analysis.

The Ethics Committee of the Institutional Review Board of the College of Medicine at King Saud University approved the study protocol (19/0134IRB). Written informed consent was obtained from all participants.

\section{Diagnostic Work-Up Of Participants}

Narcolepsy was diagnosed according to the ICSD-3 criteria. ${ }^{14}$ Following overnight polysomnography, all participants underwent an MSLT. ${ }^{14}$ In patients who were diagnosed before 2014, the ICSD-2 criteria were initially used. ${ }^{13}$ However, after the release of the ICSD- 3 criteria, the new criteria were applied to the patients diagnosed before 2014 in retrospect. NT1 was diagnosed based on irresistible attacks of sleep, a mean latency of $<8 \mathrm{~min}$ on the MSLT associated with sleep-onset REM periods (SOREMPs), and clear cataplexy ("more than one episode of generally brief [ $<2 \mathrm{~min}]$, bilateral, symmetrical, sudden loss of muscle tone with retained consciousness"). ${ }^{14}$ The attacks are triggered by strong emotional reactions, with some attacks, secondary to emotions associated with laughter, manifesting in nearly all patients. The finding of cataplexy is transient and reversible. ${ }^{14}$ At diagnosis, all patients had cataplectic attacks more than once per week. Upon recruitment, the patients have been stable with treatment for a mean of $12 \pm 4$ months. Medications for hypersomnolence, included modafinil ( $n=32)$, methylphenidate $(\mathrm{n}=4)$, and modafinil and methylphenidate $(\mathrm{n}=2)$; and for cataplexy, fluoxetine $(\mathrm{n}=28)$, venlafaxine $(n=8)$, and sodium oxybate with venlafaxine $(n=2)$. Other untreated causes of excessive daytime sleepiness were ruled out.

Human leukocyte antigen (HLA)-genotyping was performed for 12 patients; all of them were positive for the HLADQB $1 * 0602$ haplotype.

The ESS was used to determine subjective daytime sleepiness. ${ }^{15}$ We adopted an ESS change of $>4$ points as significant, based on the suggestion by recent studies on daytime sleepiness. ${ }^{12,16}$

The PSQI has been used to assess sleep quality in patients with narcolepsy, ${ }^{17,18}$ and it was used to measure sleep quality and pattern in the study group. The PSQI consists of 10 questions and has a 7-component scoring system that assesses subjective sleep quality, habitual sleep efficiency, sleep latency, sleep duration, sleep disturbances, use of sleep medications, and daytime dysfunction over the past month. ${ }^{19}$ Each item is scored on a $0-3$ scale. The PSQI score is quantified by adding the seven component scores. The overall score ranges from 0 to 21 , where lower scores represent a better sleep quality. A total score of $\geq 5$ indicates poor sleep quality.

The data on comorbidities were obtained from the participants' electronic medical files.

\section{Statistical Analysis}

Statistical Package for Social Sciences software (SPSS versions 22; IBM Corporation, Armonk, NY, USA) was used to manage and analyze data. Categorical data were expressed as number (\%), while continuous data were expressed as mean \pm standard deviation. Categorical variables were compared using the McNemar's Chi-Square test, ${ }^{20}$ while scale groups were compared using the Wilcoxon Signed Ranks Test as normality test failed. Cochran's Q Test was used in Table 4 for comparison of frequency of cataplectic attacks at 2, 6, and 10 years. ${ }^{21}$ Differences with $\mathrm{p}<0.05$ were considered statistically significant.

\section{Results}

Table 1 presents the general characteristics of the study cohort at the end of the study. The ages at disease onset and recruitment were $17.7 \pm 5.6$ years and $24.3 \pm 8.6$ years, respectively.

\section{Assessment Of Sleep Parameters, BMI, And Comorbidities}

Table 2 presents a comparison between BMI, ESS, PSQI, and comorbidities at enrollment and after 10 years. BMI increased from $30 \pm 5.1$ to $33.3 \pm 6 \mathrm{~kg} / \mathrm{m}^{2}$ ( $\mathrm{p}=0.001$ ). The mean ESS score decreased by more than 4 points from $19.4 \pm 2.9$ to $15 \pm 4.3(\mathrm{p}<0.001)$ while on the same pharmacotherapy. During the observation period, a reduction in the ESS score by $>4$ points was seen in 16 patients $(42 \%)$ and by $<4$ points in 22 patients $(58 \%)$. Four patients had an increase in the ESS score, but it was $<4$ points. Figure 2 illustrates the individual values of the ESS score at recruitment and the end of the study.

The global PSQI score decreased from $8.1 \pm 3.8$ to $6.4 \pm 3.6(\mathrm{p}=0.001)$. The number of patients with a PSQI score $<5$ (indicating good sleep quality) increased from 6 $(15.8 \%)$ to $15(39.5 \%)(\mathrm{p}=0.004)$. Figure 3 indicates the 
Table I Demographic And General Information. WASO Reflects The Duration Of Wakefulness Occurring After Defined Sleep Onset

\begin{tabular}{|l|l|}
\hline Variable Total ( $\mathbf{n}=\mathbf{3 8})$ & Mean \pm SD/n (\%) \\
\hline Age at onset (years) & $17.7 \pm 5.6$ \\
Age at recruitment (years) & $24.3 \pm 8.6$ \\
Age at the end of the study (years) & $34.5 \pm 11.8$ \\
Body mass index (kg/m $\left.{ }^{2}\right)$ & $33.3 \pm 6$ \\
Males & $27(71.1 \%)$ \\
Smokers & $4(10.5)$ \\
Educational level (High school and more) & $32(84.2)$ \\
Comorbid obstructive sleep apnea & $18(47.4)$ \\
Restless legs syndrome & $0(0)$ \\
\hline PSG findings at presentation & \\
Sleep efficiency (\%) & $81 \pm 11.2$ \\
Arousal index (arousals/h) & $20.4 \pm 14.5$ \\
Apnea hypopnea index (events/h) & $10.6 \pm 13.9$ \\
WASO (min) & $5.9 \pm 11.1$ \\
\hline MSLT findings at presentation & \\
Sleep latency (min) & $2.1 \pm 2.9$ \\
SOREM periods & $3.6 \pm 0.7$ \\
\hline
\end{tabular}

Abbreviations: SD, standard deviation; PSG, polysomnography; WASO, wake after sleep onset; MSLT, multiple sleep latency test; SOREM, sleep-onset rapid eye movement.

individual values of the PSQI score at recruitment and the end of the study. No changes were documented in comorbidities.

Figure 4 presents the individual values of the BMI at enrollment and the end of the study. BMI decreased in five patients. Two of them underwent bariatric surgery. One case is a female patient; her BMI was $40.5 \mathrm{~kg} / \mathrm{m}^{2}$ at enrollment and increased to $43 \mathrm{~kg} / \mathrm{m}^{2}$ one year before the end of the study (just before bariatric surgery). At the end of the study (1 year after surgery), her BMI decreased to $37 \mathrm{~kg} / \mathrm{m}^{2}$. The other case is a male patient; his BMI at enrollment was $41.1 \mathrm{~kg} / \mathrm{m}^{2}$ and increased to $44 \mathrm{~kg} / \mathrm{m}^{2}$ three years before the end of the study (just before bariatric surgery). Three years after surgery (at the end of the study), the BMI dropped to $26 \mathrm{~kg} / \mathrm{m}^{2}$. There were no clear medical interventions to reduce weight in the other three patients.

\section{Cataplexy}

Cataplexy manifested as complete muscle paralysis and collapse in 8 patients $(21 \%)$, and as partial muscle weakness in the rest. Partial muscle weakness appeared as knee buckling, jaw sagging, an inclination of the head, and weakness of the hand muscles. Emotional triggers included laughter in $66 \%(n=25)$ followed by anger in $34 \%(n=13$,$) and other emotions like embarrassment, sur-$ prise, nervousness, and amusement in $18 \%(n=7)$ of the patients.

Table 3 presents the discontinuation status of cataplexy medications at the end of the study. In $42 \%(n=16)$ of the cohort, the anti-cataplectic medications were stopped at the end of the study without recurrence of cataplexy. Table 4 presents the frequency of cataplexy at 2, 6, and 10 years after recruitment. There was an apparent significant reduction in the frequency of cataplexy over time.

Table 2 Comparison Between BMI, ESS, PSQI, And Comorbidities At Diagnosis And After 10 Years

\begin{tabular}{|c|c|c|c|c|c|c|c|}
\hline \multirow[t]{2}{*}{ Variable Total $(n=38)$} & \multicolumn{3}{|c|}{ At Recruitment $(n=38)$} & \multicolumn{3}{|c|}{10 Years After Diagnosis $(n=38)$} & \multirow[t]{2}{*}{ p-value } \\
\hline & Mean \pm SD/n (\%) & Std. Error & 95\% C.I. & Mean \pm SD/n (\%) & Std. Error & 95\% C.I. & \\
\hline Body mass index $\left(\mathrm{kg} / \mathrm{m}^{2}\right)$ & $30 \pm 5.1$ & 0.9 & $28.1-31.9$ & $33.3 \pm 6$ & 1.1 & $31-35.5$ & 0.001 \\
\hline Epworth Sleepiness Scale & $19.4 \pm 2.9$ & 0.5 & I8.4-20.4 & $15 \pm 4.3$ & 0.7 & $13.6-16.4$ & $<0.001$ \\
\hline \multicolumn{8}{|l|}{$\begin{array}{l}\text { Pittsburgh Sleep Quality } \\
\text { Index (PSQI) }\end{array}$} \\
\hline Global PSQI Score & $8.1 \pm 3.8$ & 0.6 & $6.9-9.4$ & $6.4 \pm 3.6$ & 0.6 & $5.2-7.5$ & 0.001 \\
\hline PSQI <5 (Good sleeper) & $6(15.8)$ & & & $15(39.5)$ & & & 0.004 \\
\hline \multicolumn{8}{|l|}{ Comorbidities } \\
\hline None & $32(84.2)$ & & & $31(81.6)$ & & & 1.000 \\
\hline Diabetes mellitus & $2(5.3)$ & & & $3(8)$ & & & 1.000 \\
\hline Hypertension & $0(0)$ & & & I (2.6) & & & 1.000 \\
\hline Bronchial asthma & $0(0)$ & & & $0(0)$ & & & - \\
\hline Allergic rhinitis & $0(0)$ & & & $0(0)$ & & & - \\
\hline Hypothyroidism & $2(5.3)$ & & & $2(5.3)$ & & & 1.000 \\
\hline Other & $2(5.3)$ & & & $2(5.3)$ & & & 1.000 \\
\hline
\end{tabular}

Abbreviation: SD, standard deviation. 


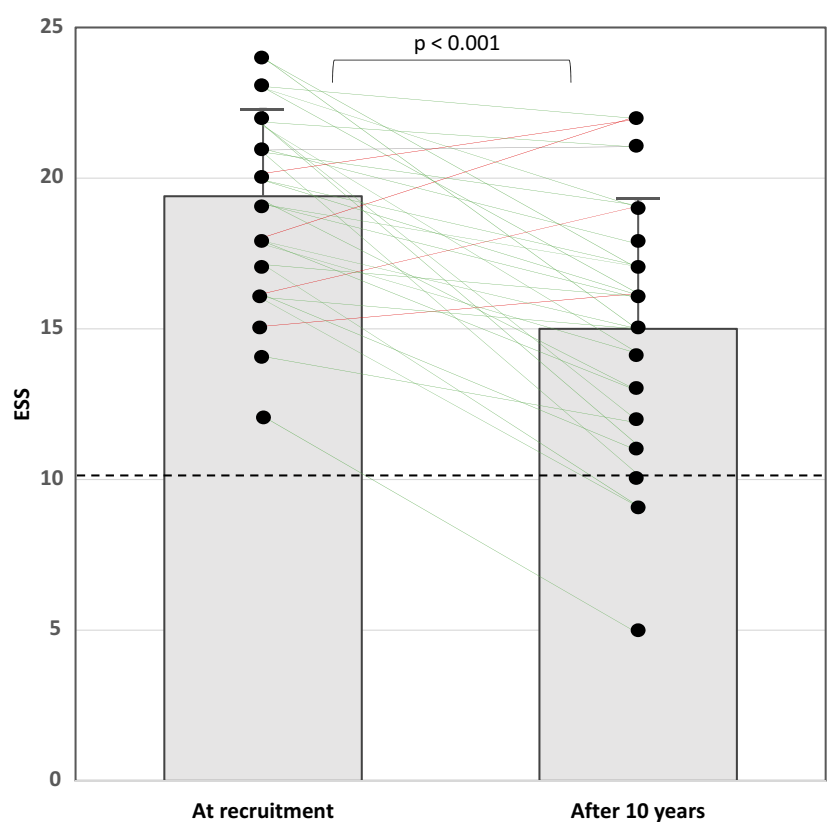

Figure 2 An illustration of the values of the ESS score at recruitment and the end of the study. The dashed black line represents the cut-off value for a "normal" ESS score ( $\leq 10$ points). The boxes demonstrate the mean and standard deviation of the ESS scores. Green lines represent patients who had an improvement in the ESS score, and the red lines represent the four patients who had an increase in the ESS score.

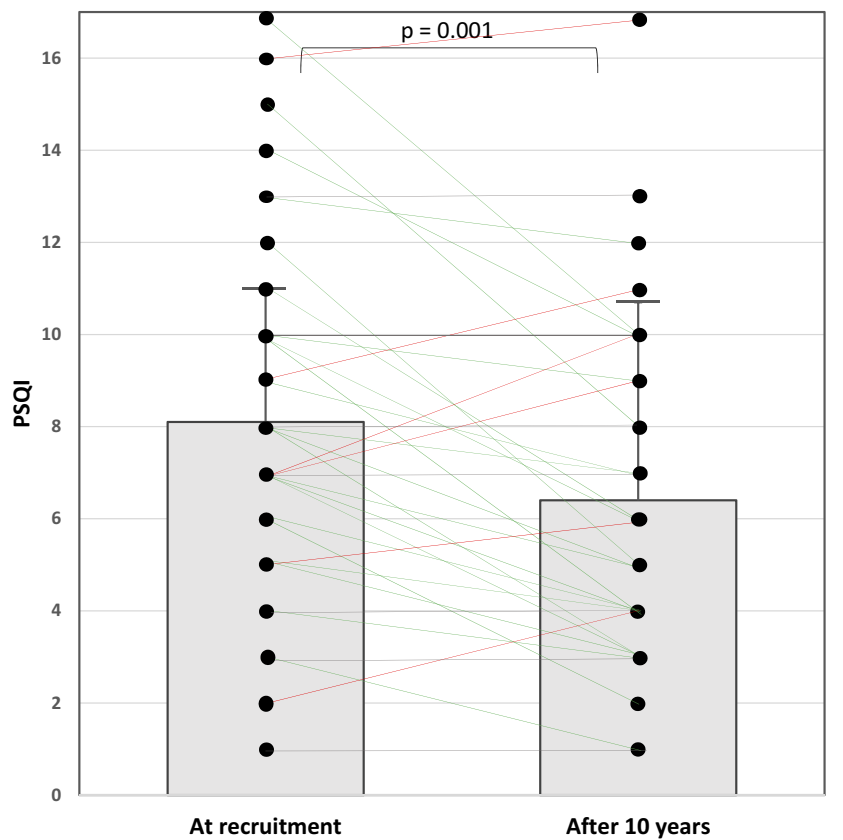

Figure 3 An illustration of the global Pittsburgh sleep quality index (PSQI) score at recruitment and the end of the study. The boxes demonstrate the mean and standard deviation of the PSQI scores. Green lines represent patients who had a decrease in the PSQI score, red lines represent patients with an increase in the PSQI score, and gray lines indicate patients with no change in the PSQI score.

\section{Discussion}

Although NT1 is considered a chronic disease with a stable course, the time-course of NT1 has never been

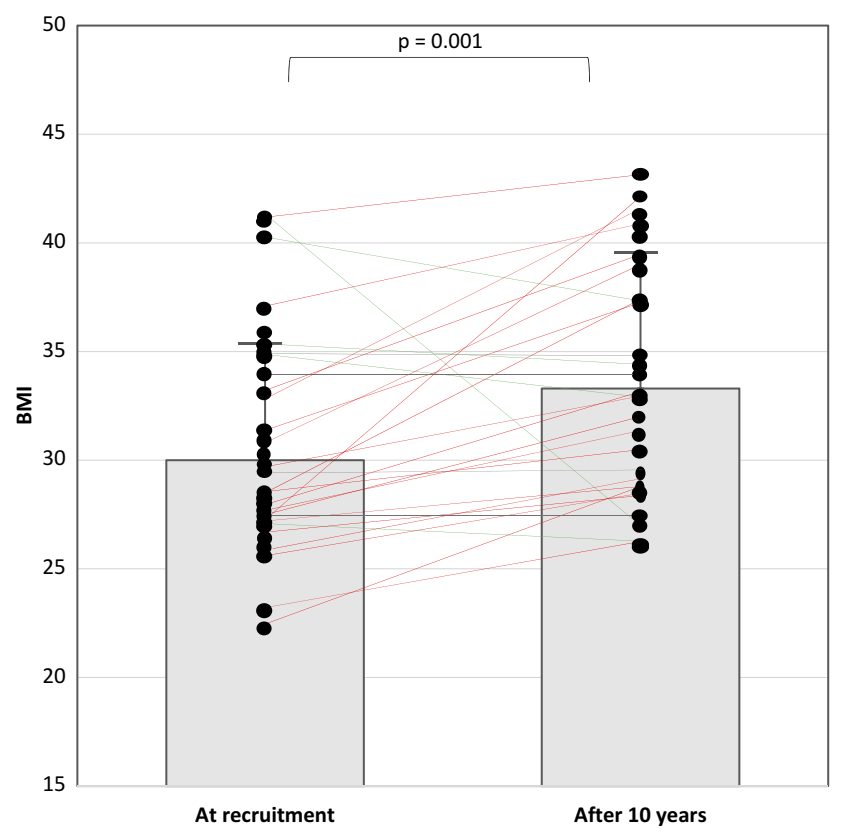

Figure 4 An illustration of the body mass index (BMI) at recruitment and the end of the study. The boxes demonstrate the mean and standard deviation of the BMI. Green lines represent patients who had a decrease in BMI; red lines represent patients with an increase in BMI.

clearly delineated, and follow-up data on the course of the frequency and severity of narcolepsy symptoms over time under stable pharmacotherapy are limited. This longitudinal study demonstrated that symptoms in patients with NT1 are not necessarily persistent for a lifetime. There was an apparent reduction in daytime sleepiness and cataplexy in a significant proportion of patients with NT1. Additionally, sleep quality reflected by the PSQI score tended to improve over time. Moreover, the current results concur with those of previous studies showing an increase in BMI during the course of narcolepsy. ${ }^{22-24}$

Longitudinal data on the course of cataplexy are scarce. It is thought that cataplexy persists throughout life, although the frequency of attacks might decrease with age. ${ }^{25,26}$ However, in this study, $42 \%$ of patients stopped anticataleptic treatment and felt that they do not need them after an average of 5.2 years. A recent report of six patients with

Table 3 Discontinuation Status Of Cataplexy Medications At The End Of The Study

\begin{tabular}{|l|l|}
\hline Variable Total $(\mathbf{n}=\mathbf{3 8})$ & Mean \pm SD/n (\%) \\
\hline $\begin{array}{l}\text { Medication of cataplexy were stopped } \\
\text { without recurrence of symptoms? (Yes) } \\
\text { Duration since stopping medications (Years) }\end{array}$ & $16(42)$ \\
\hline
\end{tabular}

Abbreviation: SD, standard deviation. 
Table 4 The Frequency Of Cataplectic Attacks 2, 6, And 10 Years After Diagnosis With No Escalation Of Treatment

\begin{tabular}{|c|c|c|c|c|}
\hline Cataplexy & $\begin{array}{l}2 \text { Years From } \\
\text { Recruitment } \\
(n=38), n(\%)\end{array}$ & $\begin{array}{l}6 \text { Years From } \\
\text { Recruitment } \\
(n=38), n(\%)\end{array}$ & $\begin{array}{l}\text { I0 Years From } \\
\text { Recruitment } \\
(n=38), n(\%)\end{array}$ & p-value \\
\hline One or less cataplectic attack per year & $14(36.8)$ & $19(50)$ & 27 (7I) & $<0.001$ \\
\hline $\begin{array}{l}\text { More than one cataplectic attack per year but Less than one } \\
\text { cataplectic attack per month }\end{array}$ & $5(13.2)$ & $5(13.2)$ & $3(8)$ & 0.135 \\
\hline $\begin{array}{l}\text { More than one cataplectic attack per month but less than one } \\
\text { attack per week }\end{array}$ & $10(26.3)$ & $9(23.6)$ & $5(13)$ & 0.015 \\
\hline $\begin{array}{l}\text { More than one cataplectic attack per week but less than one } \\
\text { attack per day }\end{array}$ & $2(5.3)$ & $4(10.5)$ & $3(8)$ & 0.223 \\
\hline At least one cataplectic attack per day & $7(18.4)$ & I (2.6) & $0(0)$ & 0.002 \\
\hline
\end{tabular}

NT1 revealed that in two patients, cataplexy attacks disappeared during follow up under drug-free conditions. ${ }^{27} \mathrm{An}$ earlier report compared changes in narcolepsy symptoms between 50 (age $\geq 65$ years) and 34 patients (age $<65$ years [younger group]) and reported significantly lower scores for cataplexy in the aged group, ${ }^{9}$ suggesting that with increased age, cataplexy symptoms may decrease.

A previous study in children with narcolepsy and cataplexy demonstrated that hypotonia symptoms slowly decreased over time, and "spontaneous" cataplexy (head drops and falls without apparent emotional stimuli) was replaced over time with the appearance of classical cataplexy episodes triggered by emotions. ${ }^{28}$ This suggests that the course of cataplexy is not stationary and that it changes over time. A study in an equine model of familial narcolepsy revealed an improvement in spontaneous joint buckling and falls over 2 years of follow-up time. ${ }^{29}$

Moreover, spontaneous improvement in cataplexy intensity and frequency over the course of the disease has been reported in drug-free adults and children with HCRT deficiency. ${ }^{2,5}$ Recently, Lopez et al reported a young patient with NT1 and cerebrospinal fluid (CSF)-HCRT level of 106 $\mathrm{pg} / \mathrm{mL}$, one year after the onset of sleepiness, with remission of cataplexy within two years despite a further decline of CSF-HCRT level to $27 \mathrm{pg} / \mathrm{mL} .{ }^{27}$ These reports suggest that additional mechanisms and neurotransmitters other than HCRT are involved in cataplexy development. An improvement in these other mechanisms may result in improvement in cataplexy frequency and severity in some patients. Pizza et al suggested that compensatory mechanisms may occur within the central nervous system, despite stable low HCRT levels. ${ }^{2}$ Functional studies in patients with NT1 demonstrated adjusted emotional processing by cortical and subcortical structures as a function of disease duration. ${ }^{30,31}$
Although there is no consensus on the mechanisms causing narcolepsy, the presence of auto-antibodies, HLA links, and familial predisposition point to autoimmune pathogenesis. ${ }^{32,33}$ Autoimmune diseases often demonstrate clinical improvement in the course of the disorders over time after an abrupt acute onset phase. ${ }^{34}$ This improvement in the course of autoimmune disorders could apply to narcolepsy. Further studies to assess the course of cataplexy are needed to unravel whether internal adaptive compensatory processes, a partial spontaneous remission process, or a combination of both explain the clinical improvement in cataplexy.

The current study demonstrated an improvement in subjective sleepiness reflected by a reduction in the ESS score by more than 4 points at the end of the study. A recent retrospective study of 26 HCRT-deficient NT1 patients on stable pharmacotherapy longitudinally assessed the ESS scores (a mean observation period of 5 years) and reported considerable changes in subjective sleepiness (a reduction of $>4$ points changes in the ESS score), including both spontaneous improvement (15\%) and deterioration (12\%). ${ }^{12}$ Moreover, MSLT values normalized in two patients without pharmacotherapy. ${ }^{12}$ To assess the relationship between improvement in sleepiness and the CSF-HCRT level, the investigators repeated CSF-HCRT measurements in two patients and reported a discrepancy between clinical improvement and progressive HRCT deficiency. ${ }^{12}$ This finding again challenges the traditional concept of HRCT as the sole NT1 biomarker. ${ }^{12}$ However, as daytime sleepiness was measured subjectively in this study, it is possible that patients may develop certain skills to fight the feeling of sleepiness and have better utilization of the countermeasures of sleepiness over time. 
Disturbed or poor quality nighttime sleep is a frequent complaint among patients with narcolepsy, with a reported prevalence ranging from $30 \%$ to $95 \%$, depending on the criteria used to define sleep disturbances. ${ }^{35}$ In the current study, the proportion of patients with a PSQI score $<5$ increased from $15.8 \%$ to $39.5 \%$ ( $\mathrm{p}=0.004$ ). We could not find any previous study that has longitudinally assessed sleep quality in patients with NT1. Recently, Büchele et al reported that undisturbed nighttime sleep in narcolepsy patients might predict a more favorable disease course. ${ }^{12}$ It is possible that symptoms of narcolepsy are not stable and may change over time.

The loss of HCRT signaling cannot explain the improvement of hypersomnolence over time or the improvement in nighttime sleep quality. This means that the loss of HCRT signaling is not the only change that occurs in patients with NT1. ${ }^{36}$ There is evolving evidence supporting that sleep/wake regulating nuclei possess a potential of neuroplasticity. ${ }^{36}$ Two independent groups have demonstrated markedly increased numbers of histaminergic neurons in the tuberomammillary nucleus of patients with NT1. ${ }^{37,38}$ This increase in the histaminergic neurons may reflect a compensatory mechanism to loss of excitatory effect from the HCRT neurons and may contribute to the observed improvement in hypersomnolence. However, this cannot be the sole mechanism as increased histamine signaling has been proposed as one of the mechanisms that contribute to fragmented nighttime sleep, ${ }^{36}$ and in the present study, we have shown that the quality of sleep improved over time. Büchele et al proposed that in patients with measurable HCRT levels, surviving HCRT neurons may compensate for the reduced number of neurons by increasing efficiency of surviving HCRT neurons, which hypothetically may more effectively counterbalance the reduced signaling, by boosting synaptic strength to other nuclei involved in sleep/wake regulation. ${ }^{12}$ This topic warrants more research to define the different mechanisms involved in the dynamic course of narcolepsy.

Although the participants in this study were overweight and obese at recruitment, they gained weight during the follow-up period. In a study that assessed BMI at baseline and 10 years later in nine patients with NT1 and nine patients with NT2 matched for age and sex, BMI increased in all patients from $26.8 \pm 0.9 \mathrm{~kg} / \mathrm{m}^{2}$ to $29.23 \pm 0.91 \mathrm{~kg} / \mathrm{m}^{2}$ $(\mathrm{p}=0.001)$ after 10 years of follow up. ${ }^{22}$ Studies have shown that children with NT1 can gain $5-15 \mathrm{~kg}$ in a short time and that adults with NT1 are usually overweight or obese at diagnosis, despite normal activity levels and caloric intake. ${ }^{23,24,39,40}$ Mouse model of narcolepsy (lacking HRCT) revealed obesity with a lower metabolic rate. ${ }^{41}$ However, in humans with NT1, research on metabolic rate is still inconclusive. ${ }^{24,42}$

The increase in BMI despite improvement in other symptoms is probably related to HRCT deficiency. Sellayah et al demonstrated that in HRCT-null mice, obesity was associated with impaired thermogenesis of brown adipose tissue, due to the inability of brown preadipocytes to differentiate. ${ }^{25}$ This reduction in thermogenesis leads to a reduction in energy expenditure. HRCT injection into the mice model prevented weight gain. ${ }^{25}$ Moreover, HRCT has been shown to play a significant role in regulating muscle glucose metabolism. ${ }^{43}$ These findings are supported by data showing that despite decreased caloric intake, ${ }^{44}$ patients with narcolepsy gained weight. ${ }^{23}$ More studies are needed to examine eating and exercise habits and metabolic rate changes in patients with NT1 to help practitioners defining the best treatment modality to control weight gain in this group of patients.

This work has limitations that need to be acknowledged. First, CSF-HCRT levels were not measured; however, we strictly followed the ICSD-3 criteria for diagnosing NT1. Second, we only included patients who were stable on pharmacotherapy; therefore, the results cannot be extrapolated to NT1 patients who require frequent modifications of pharmacotherapy. Third, this study was primarily designed to assess the time-course of cataplexy; therefore, data for other parameters were collected only at recruitment and 10 years later.

\section{Conclusion}

Our results suggest that patients with NT1 may have a spontaneous improvement in symptomatology over time. Over a 10-year period, cataplexy symptoms improved or disappeared in a large proportion of patients. Moreover, there was an improvement in daytime sleepiness and nighttime sleep quality in NT1 patients on stable pharmacotherapy. The current findings challenge the belief that NT1 is a chronic, persistent disorder. More prospective studies that repeatedly monitor CSF-HCRT are needed to confirm the current findings.

\section{Abbreviations}

REM, Rapid eye movement; NT1, Narcolepsy type 1; NT2, Narcolepsy type 2; HCRT, Hypocretin (orexin); MSLT, Multiple sleep latency test; BMI, Body mass 
index; ESS, Epworth sleepiness scale; PSQI, Pittsburgh sleep quality index; ICSD, International Classification of Sleep Disorders; HLA, Human leukocyte antigen; CSF, Cerebrospinal fluid.

\section{Ethics Approval And Informed Consent}

The Ethics Committee of the Institutional Review Board of the College of Medicine at King Saud University approved the study protocol (19/0134IRB). Written informed consent was obtained from all participants. The study was conducted in accordance with the Declaration of Helsinki.

\section{Data Availability}

Data are available but need institutional approval before sharing.

\section{Acknowledgments}

This study was supported by a grant from the Researchers Supporting Project number (RSP-2019/51). King Saud University, Riyadh Saudi Arabia. The grant was obtained by Prof. Ahmed S. BaHammam. The study sponsors played no role in the study design; collection, analysis, or interpretation of the data; writing of the manuscript; or decision to submit the manuscript.

\section{Author contributions}

ASA: Conception of idea, data analysis, writing the manuscript, final edit, approval of the manuscript, and agreement to be accountable for all aspects of the work in ensuring that questions related to the accuracy or integrity of any part of the work are appropriately investigated and resolved.

NA: Data collection, data analysis, final edit and approval of the manuscript, and agreement to be accountable for all aspects of the work in ensuring that questions related to the accuracy or integrity of any part of the work are appropriately investigated and resolved.

BA: Data collection, data analysis, final edit, approval of the manuscript, and agreement to be accountable for all aspects of the work in ensuring that questions related to the accuracy or integrity of any part of the work are appropriately investigated and resolved.

SA: Data collection, data analysis, final edit and approval of the manuscript, and agreement to be accountable for all aspects of the work in ensuring that questions related to the accuracy or integrity of any part of the work are appropriately investigated and resolved.

AHO: Data analysis, writing the manuscript, final edit and approval of the manuscript, and agreement to be accountable for all aspects of the work in ensuring that questions related to the accuracy or integrity of any part of the work are appropriately investigated and resolved.

ASB: Conception of idea, data collection, securing grant, data analysis, writing the manuscript, final edit and approval of the manuscript, and agreement to be accountable for all aspects of the work in ensuring that questions related to the accuracy or integrity of any part of the work are appropriately investigated and resolved.

\section{Disclosure}

The authors report no conflict of interest in this work.

\section{References}

1. Zhang J, Han F. Sleepiness in narcolepsy. Sleep Med Clin. 2017;12 (3):323-330. doi:10.1016/j.jsmc.2017.03.008

2. Pizza F, Franceschini C, Peltola H, et al. Clinical and polysomnographic course of childhood narcolepsy with cataplexy. Brain. 2013;136(Pt 12):3787-3795. doi:10.1093/brain/awt277

3. Dauvilliers Y, Arnulf I, Mignot E. Narcolepsy with cataplexy. Lancet. 2007;369(9560):499-511. doi:10.1016/S0140-6736(07)60237-2

4. Dauvilliers Y, Siegel JM, Lopez R, Torontali ZA, Peever JH. Cataplexy-clinical aspects, pathophysiology and management strategy. Nat Rev Neurol. 2014;10(7):386-395. doi:10.1038/ nrneurol.2014.97

5. Dauvilliers Y, Gosselin A, Paquet J, Touchon J, Billiard M, Montplaisir J. Effect of age on MSLT results in patients with narcolepsy-cataplexy. Neurology. 2004;62(1):46-50. doi:10.1212/01. wnl.0000101725.34089.1e

6. Nevsimalova S, Buskova J, Kemlink D, Sonka K, Skibova J. Does age at the onset of narcolepsy influence the course and severity of the disease? Sleep Med. 2009;10(9):967-972. doi:10.1016/j. sleep.2009.01.010

7. Ohayon MM, Ferini-Strambi L, Plazzi G, Smirne S, Castronovo V. How age influences the expression of narcolepsy. J Psychosom Res. 2005;59(6):399-405. doi:10.1016/j.jpsychores.2005.06.065

8. Cairns A, Trotti LM, Bogan R. Demographic and nap-related variance of the MSLT: results from 2,498 suspected hypersomnia patients: clinical MSLT variance. Sleep Med. 2019;55:115-123. doi:10.1016/j.sleep.2018.12.013

9. Furuta H, Thorpy MJ, Temple HM. Comparison in symptoms between aged and younger patients with narcolepsy. Psychiatry Clin Neurosci. 2001;55(3):241-242. doi:10.1046/j.14401819.2001.00841.x

10. Billiard M, Besset A, Cadilhac J. The clinical and polygraphic development of narcolepsy. In: Guilleminault C, Lugaresi E, editors. Sleep/wake Disorders: Natural History, Epidemiology, and LongTerm Evolution. New York: Raven Press; 1983:171-185.

11. Bruck D, Costa A. The natural history of health and symptoms in narcolepsy: a 10 year longitudinal study. Aust J Prim Health. 2003;9 (1):59-67. doi:10.1071/PY03007

12. Büchele F, Baumann CR, Poryazova R, Werth E, Valko PO. Remitting narcolepsy? Longitudinal observations in a hypocretindeficient cohort. Sleep. 2018;41(9). doi:10.1093/sleep/zsy024 
13. American Academy of Sleep Medicine. International Classification of Sleep Disorders (ICSD-2): Diagnostic and Coding Manual. 2nd ed. Westchester (IL): American Academy of Sleep Medicine; 2005.

14. American Academy of Sleep Medicine (AASM). International Classification of Sleep Disorders (ICSD). 3rd ed. Darien (IL): AASM. 2014.

15. Johns MW. A new method for measuring daytime sleepiness: the Epworth sleepiness scale. Sleep. 1991;14(6):540-545. doi:10.1093/ sleep/14.6.540

16. Jaussent I, Morin CM, Ivers H, Dauvilliers Y. Incidence, worsening and risk factors of daytime sleepiness in a population-based 5-year longitudinal study. Sci Rep. 2017;7(1):1372. doi:10.1038/s41598017-01547-0

17. Buysse DJ, Reynolds CF 3rd, Monk TH, Berman SR, Kupfer DJ. The Pittsburgh Sleep Quality Index: a new instrument for psychiatric practice and research. Psychiatry Res. 1989;28(2):193-213. doi:10.1016/0165-1781(89)90047-4

18. Dauvilliers Y, Roth T, Guinta D, Alvarez-Horine S, Dynin E, Black J. Effect of sodium oxybate, modafinil, and their combination on disrupted nighttime sleep in narcolepsy. Sleep Med. 2017;40:53-57. doi:10.1016/j.sleep.2017.07.030

19. Carpenter JS, Andrykowski MA. Psychometric evaluation of the Pittsburgh Sleep Quality Index. J Psychosom Res. 1998;45(1):5-13. doi:10.1016/S0022-3999(97)00298-5

20. Dayton CM. A reinterpretation and extension of McNemar's test. $J$ Mod Appl Stat Meth. 2017;16:20-33. doi:10.22237/jmasm/ 1493596860

21. Cleophas TJ, Zwinderman AH. Repeated measures binary data (Cochran's Q Test), (139 Patients). In: SPSS for Starters and 2nd Levelers. Cham (Swizeland): Springer, Cham; 2016:249-252. doi: org/10.1007/978-3-319-20600-4_43

22. Cremaschi RC, Hirotsu C, Tufik S, Coelho FM. Narcolepsy type 1 and type 2 - a 10-year follow-up: body mass index and comorbidities. Sleep Med. 2017;32:285-286. doi:10.1016/j.sleep.2016.12.003

23. Schuld A, Hebebrand J, Geller F, Pollmacher T. Increased body-mass index in patients with narcolepsy. Lancet. 2000;355(9211):1274 1275. doi:10.1016/S0140-6736(05)74704-8

24. Wang Z, Wu H, Stone WS, et al. Body weight and basal metabolic rate in childhood narcolepsy: a longitudinal study. Sleep Med. 2016;25:139-144. doi:10.1016/j.sleep.2016.06.019

25. American Sleep Disorders Association and Sleep Research Society. EEG arousals: scoring rules and examples: a preliminary report from the Sleep Disorders Atlas Task Force of the American Sleep Disorders Association. Sleep. 1992;15(2):173-184.

26. Mattarozzi K, Bellucci C, Campi C, et al. Clinical, behavioural and polysomnographic correlates of cataplexy in patients with narcolepsy/cataplexy. Sleep Med. 2008;9(4):425-433. doi:10.1016/j. sleep.2007.05.006

27. Lopez R, Barateau L, Evangelista E, et al. Temporal changes in the cerebrospinal fluid level of hypocretin-1 and histamine in narcolepsy. Sleep. 2017;40(1). doi:10.1093/sleep/zsw010

28. Plazzi G, Pizza F, Palaia V, et al. Complex movement disorders at disease onset in childhood narcolepsy with cataplexy. Brain. 2011;134(Pt 12):3477-3489. doi:10.1093/brain/awr244
29. Ludvikova E, Nishino S, Sakai N, Jahn P. Familial narcolepsy in the Lipizzaner horse: a report of three fillies born to the same sire. Vet $Q$. 2012;32(2):99-102. doi:10.1080/01652176.2012.714089

30. Ponz A, Khatami R, Poryazova R, et al. Abnormal activity in reward brain circuits in human narcolepsy with cataplexy. Ann Neurol. 2010;67(2):190-200. doi:10.1002/ana.21825

31. Schwartz S, Ponz A, Poryazova R, et al. Abnormal activity in hypothalamus and amygdala during humour processing in human narcolepsy with cataplexy. Brain. 2008;131(Pt 2):514-522. doi:10.1093/brain/awm292

32. Al Shareef SM, AlAnbay E, AlKhathlan MA, et al. HLADQB1*06:02 allele frequency and clinic-polysomnographic features in Saudi Arabian patients with narcolepsy. Sleep Breath. 2019;23 (1):303-309. doi:10.1007/s11325-018-1717-4

33. Alomar M, Almeneessier AS, Olaish AH, Alshiban A, Alomar A, BaHammam AS. Immune-mediated comorbidities in Saudi patients with narcolepsy. Nat Sci Sleep. 2019;11:35-43. doi:10.2147/NSS. S195650

34. Hayter SM, Cook MC. Updated assessment of the prevalence, spectrum and case definition of autoimmune disease. Autoimmun Rev. 2012;11(10):754-765. doi:10.1016/j.autrev.2012.02.001

35. Roth T, Dauvilliers Y, Mignot E, et al. Disrupted nighttime sleep in narcolepsy. J Clin Sleep Med. 2013;9(9):955-965. doi:10.5664/ jcsm.3004

36. Mahoney CE, Cogswell A, Koralnik IJ, Scammell TE. The neurobiological basis of narcolepsy. Nat Rev Neurosci. 2019;20(2):83-93. doi:10.1038/s41583-018-0097-x

37. John J, Thannickal TC, McGregor R, et al. Greatly increased numbers of histamine cells in human narcolepsy with cataplexy. Ann Neurol. 2013;74(6):786-793. doi:10.1002/ana.23968

38. Valko PO, Gavrilov YV, Yamamoto M, et al. Increase of histaminergic tuberomammillary neurons in narcolepsy. Ann Neurol. 2013;74 (6):794-804. doi:10.1002/ana.24019

39. Ponziani V, Gennari M, Pizza F, Balsamo A, Bernardi F, Plazzi G Growing up with type 1 narcolepsy: its anthropometric and endocrine features. J Clin Sleep Med. 2016;12(12):1649-1657. doi:10.5664/ jcsm. 6352

40. van Holst RJ, van der Cruijsen L, van Mierlo P, et al. Aberrant food choices after satiation in human orexin-deficient narcolepsy type 1 . Sleep. 2016;39(11):1951-1959. doi:10.5665/sleep.6222

41. Tabuchi S, Tsunematsu T, Black SW, et al. Conditional ablation of orexin/hypocretin neurons: a new mouse model for the study of narcolepsy and orexin system function. $J$ Neurosci. 2014;34 (19):6495-6509. doi:10.1523/JNEUROSCI.0073-14.2014

42. Fronczek R, Overeem S, Reijntjes R, Lammers GJ, van Dijk JG, Pijl $\mathrm{H}$. Increased heart rate variability but normal resting metabolic rate in hypocretin/orexin-deficient human narcolepsy. J Clin Sleep Med. 2008;4(3):248-254.

43. Shiuchi T, Haque MS, Okamoto S, et al. Hypothalamic orexin stimulates feeding-associated glucose utilization in skeletal muscle via sympathetic nervous system. Cell Metab. 2009;10(6):466-480. doi:10.1016/j.cmet.2009.09.013

44. Lammers GJ, Pijl H, Iestra J, Langius JA, Buunk G, Meinders AE. Spontaneous food choice in narcolepsy. Sleep. 1996;19(1):75-76. doi:10.1093/sleep/19.1.75

\section{Publish your work in this journal}

Nature and Science of Sleep is an international, peer-reviewed, open access journal covering all aspects of sleep science and sleep medicine, including the neurophysiology and functions of sleep, the genetics of sleep, sleep and society, biological rhythms, dreaming, sleep disorders and therapy, and strategies to optimize healthy sleep.
The manuscript management system is completely online and includes a very quick and fair peer-review system, which is all easy to use. Visit http://www.dovepress.com/testimonials.php to read real quotes from published authors. 